Cranio-Maxillofacial Surgery

Elsevier Editorial System(tm) for Journal of Manuscript Draft

Manuscript Number: JCMS-D-16-00906R1

Title: Motivation for orthognathic treatment and anticipated satisfaction levels - a two-centre cross-national audit

Article Type: Original Paper

Keywords: Orthognathic surgery, motivation, satisfaction, confidence, demographics, audit

Corresponding Author: Dr. Raphael Patcas, PD Dr. med. dent., Ph.D.

Corresponding Author's Institution: University Zurcih

First Author: Raphael Patcas, PD Dr. med. dent., Ph.D.

Order of Authors: Raphael Patcas, PD Dr. med. dent., Ph.D.; Susan J Cunningham; Justin Shute; Timothy Lloyd; Joachim A Obwegeser; Lida Arjomand; Sujata Sharma

Abstract: This audit investigated factors which motivate patients to seek orthognathic treatment, assessed how confident patients were that they would be satisfied with the outcome of treatment, and explored possible influencing factors.

Questionnaires were distributed to pre-surgical patients at two centres (UK and Switzerland); questions asked what patients wished to gain from orthognathic treatment and how confident they were that they would be satisfied with treatment outcome. Gender, age, and location were recorded as demographic variables and type of malocclusion was also recorded. Two hundred and two questionnaires were returned (UK n=149; Switzerland $\mathrm{n}=53$ ). Reported motivating factors focused on improvements in aesthetics (specified and unspecified) (UK Vs. Switzerland: 91.3\% Vs. 83.0\%), function (72.5\% vs. 66.0\%), psychosocial health (51.7\% vs. 20.8\%), speech (4.0\% Vs. $7.5 \%$ ), alleviation of pain (5.4\% Vs. $17 \%$ ) and normalization of breathing ( $1.3 \%$ vs. $7.5 \%$ ). No significant relationships were observed relative to patient's age, gender or malocclusion. The anticipated satisfaction levels were generally high (86.5\% vs. 89.9\%).

Although the distribution of motivational factors varied between the two sites, it did not affect the anticipated satisfaction level. Patients were generally confident that they would be satisfied with their treatment outcome and that their reasons for seeking treatment would be addressed. 


\title{
Motivation for orthognathic treatment and anticipated satisfaction levels - a two-centre cross-national audit
}

\author{
Authors: Raphael Patcas, ${ }^{1}$ Susan J Cunningham, ${ }^{2}$ Justin Shute, ${ }^{3}$ Timothy Lloyd, ${ }^{4}$ Joachim A \\ Obwegeser, ${ }^{5}$ Lida Arjomand, ${ }^{6}$ Sujata Sharma ${ }^{7}$
}

\section{${ }^{1}$ Raphael Patcas}

Highest academic degrees: PD Dr. med. dent., PhD

Institution: Clinic for Orthodontics and Paediatric Dentistry, Centre for Dental Medicine, University of Zurich, Switzerland

Address: Plattenstrasse 11, 8032 Zurich Switzerland

Head: Prof. Theodore Eliades, DDS, MS, Dr Med Sci, PhD

\section{${ }^{2}$ Susan J Cunningham}

Highest academic degrees: PhD, BChD, FDSRCS (Orth), MSc; MOrthRCS, FHEA

Institution: Department of Orthodontics, UCL Eastman Dental Institute, London, UK

Address: 256 Gray's Inn Road, London WC1X 8LD, UK

Head: Prof. Stephen Porter, PhD, MD, MBBS, BDS, BSc (Hons), FHEA

${ }^{3}$ Justin Shute

Highest academic degrees: MBBS, MRCPysch, MSc (UCL)

Institution: Eastman Dental Hospital, University College London Hospitals NHS Foundation Trust, UK

Address: 256 Gray's Inn Road, London WC1X 8LD, UK

Head/Clinical Director of the Eastman Dental Hospital UCLH Foundation NHS Trust: Dr. Tim

Hodgson, BDS, MRCP (UK), FDS RCS (Eng)

\section{${ }^{4}$ Timothy Lloyd}

Highest academic degrees: MBBS, BDS, FRCS (OMFS)

Institution: Department of Oral and Maxillofacial Surgery, Division of Growth and Development, Eastman Dental Hospital, University College London Hospitals NHS Foundation Trust, UK Address: 256 Gray's Inn Road, London WC1X 8LD, UK

Head/Clinical Director of the Eastman Dental Hospital UCLH Foundation NHS Trust: Dr. Tim Hodgson, BDS, MRCP (UK), FDS RCS (Eng)

\section{${ }^{5}$ Joachim A Obwegeser}

Highest academic degrees: Prof. Dr. med. univ. et dent.

Affiliation: Limmat Cleft- and Craniofacial Centre, Hardturmstrasse 133, 8005 Zürich, Switzerland (Head: Prof. Joachim Obwegeser), and Department of Oral and Maxillofacial Surgery, University Children's Hospital Zurich, Steinwiesenstrasse 75, 8032 Zurich, Switzerland (Head: Prof. Dr. med. Martin Meuli)

\section{${ }^{6}$ Lida Arjomand}

Highest academic degrees: BChD, MJDF RCS (Eng), MClinDent (Ortho), MOrth(Eng) Institution: Department of Orthodontics, Eastman Dental Hospital, University College London Hospitals NHS Foundation Trust, UK

Address: 256 Gray's Inn Road, London WC1X 8LD, UK

Head: Prof. Stephen Porter, PhD, MD, MBBS, BDS, BSc (Hons), FHEA

\section{${ }^{7}$ Sujata Sharma}

Highest academic degrees: FDS RCS (Orth), MOrth (RCS.Eng), MClinDent Orthodontics (UCL), MJDF (RCS.Eng), BDS Lond. (Hons.)

Institution: Department of Orthodontics, Eastman Dental Hospital, University College London

Hospitals NHS Foundation Trust, UK

Address: 256 Gray's Inn Road, London WC1X 8LD, UK

Head: Prof. Stephen Porter, PhD, MD, MBBS, BDS, BSc (Hons), FHEA 
Corresponding author:

PD Dr. med. dent. Raphael Patcas, PhD

Centre for Dental Medicine

Clinic for Orthodontics and Paediatric Dentistry

University of Zurich

Plattenstr. 11

8032 Zürich, Switzerland

T: +41 446343289

E: raphael.patcas@,zzm.uzh.ch

Sources of support in the form of grants: None

This research did not receive any specific grant from funding agencies in the public, commercial, or not-for-profit sectors. 


\section{Motivation for orthognathic treatment and anticipated}

\section{satisfaction levels - a two-centre cross-national audit}

\section{Summary}

This audit investigated factors which motivate patients to seek orthognathic treatment, assessed how confident patients were that they would be satisfied with the outcome of treatment, and explored possible influencing factors.

Questionnaires were distributed to pre-surgical patients at two centres (UK and Switzerland); questions asked what patients wished to gain from orthognathic treatment and how confident they were that they would be satisfied with treatment outcome. Gender, age, and location were recorded as demographic variables and type of malocclusion was also recorded.

Two hundred and two questionnaires were returned (UK n=149; Switzerland n=53). Reported motivating factors focused on improvements in aesthetics (specified and unspecified) (UK vs. Switzerland: $91.3 \%$ vs. 83.0\%), function $(72.5 \% \quad v s . \quad 66.0 \%)$, psychosocial health (51.7\% vs. $20.8 \%)$, speech (4.0\% vs. $7.5 \%)$, alleviation of pain $(5.4 \% v s$. $17 \%)$ and normalization of breathing (1.3\% vs. $7.5 \%)$. No significant relationships were observed relative to patient's age, gender or malocclusion. The anticipated satisfaction levels were generally high $(86.5 \%$ vs. $89.9 \%)$.

Although the distribution of motivational factors varied between the two sites, it did not affect the anticipated satisfaction level. Patients were generally confident that they would be satisfied with their treatment outcome and that their reasons for seeking treatment would be addressed.

Key words: Orthognathic surgery, motivation, satisfaction, confidence, demographics, audit 


\section{Motivation for orthognathic treatment and anticipated}

\section{satisfaction levels - a two-centre cross-national audit}

\section{Introduction}

Orthognathic treatment refers to the management of the functional and aesthetic consequences of severe dentofacial deformity through a combination of orthodontics and maxillofacial surgery. It aims to produce more harmonious facial and skeletal relationships and improve occlusal functionality. Patients present to clinicians for a number of reasons (Cunningham and Johal, 2015) and these may include concerns regarding facial or dental appearance, psycho-social issues and functional impairments associated with eating, speaking or breathing (Alanko et al., 2010).

Orthognathic treatment is an elective process. This accentuates the importance of understanding the patient's reasons for seeking treatment and their expectations, as these factors help clinicians determine whether the benefits of treatment outweigh the risks for each individual. The need to elicit and discuss patient's wishes is instrumental for post-treatment success (Oland et al., 2011); this is particularly important with regards to aesthetics, as patients may perceive themselves differently from how their clinicians see them (Chew et al., 2007). It is well established that post-treatment success is linked to pre-treatment motivation and expectations and that unrealistic wishes may contribute to post-treatment dissatisfaction (Nurminen et al., 1999; Espeland et al., 2008; Oland et al., 2011). In order to fully understand the reasons for seeking orthognathic treatment, and the expectations associated with this, efforts have been made to categorize these reasons, for example by dividing expectations into physical and non-physical (Ryan et al., 2012b). However, less attention has been devoted to the question of whether the reasons for seeking orthognathic treatment are influenced by factors, including age, gender or type of malocclusion. There is no doubt that an enhanced 
understanding of these issues would be advantageous when managing the complex issue of patient expectations.

Another important aspect of care is the patient's degree of confidence in the proposed treatment and their confidence in the surgeons and orthodontists involved in their care. Presurgical anticipation of problems has been suggested as a significant predictor of posttreatment dissatisfaction and poorer psychological outcome (Kiyak et al., 1988). However, failing to fully discuss with patients whether or not their reasons for seeking treatment will be addressed may result in disappointment and post-treatment dissatisfaction. The patient's degree of confidence in the outcome may well be affected by their confidence in the decision to proceed with treatment, their confidence in the procedure itself and in the physicians, the clinic or the health system carrying out the procedure. Clearly these variables will differ from one patient to another. Hence, the evaluation of patient confidence should not be restricted to a simple report, but should attempt to clarify whether the envisaged satisfaction is affected by location, age, gender or type of malocclusion. Moreover, conducting a two-centre audit in different countries allows a more thorough interpretation of any effects and strengthens the generalizability of the results.

The aims of this cross-national two-centre audit were therefore (i) To understand the factors that motivate patients to seek orthognathic treatment (ii) To measure how confident patients were that they would be satisfied with their treatment and (iii) To investigate the possible influence of demographic factors. 


\section{Patients and methods}

This two-centre audit was conducted at in the UK and in Switzerland. In both centres, all consecutive patients enrolled for orthognathic treatment were given a questionnaire. In the UK centre, this included all pre-treatment orthognathic patients attending the joint multidisciplinary clinic between June 2013 and January 2016. Data from the Swiss centre was collected between December 2014 and January 2016.

The questionnaire consisted of two sections: the first section asked patients to list up to five things they would like to gain from treatment and was formulated as open-ended question. For the purpose of this paper, the responses to this question will be referred to as the 'motivating factors'. Prior to analysis, these motivating factors were categorized independently by two researchers, to ensure agreement. The second section of the questionnaire asked how confident the patient was that they would be satisfied with the outcomes of their treatment (score 0-100\%). The patient's age, gender, and type of malocclusion (Class II, Class III, anterior open bite, deep bite, facial asymmetry) were recorded, but no other data was collected to ensure anonymity.

All questionnaires were given to patients by clinicians who were familiar with the questionnaire and were part of the orthognathic team and patients were asked to return completed forms to the reception staff. A researcher not involved in the patients' treatment received the anonymised data for statistical analysis. Ethical guidelines (World Medical Association (WMA), 2013) were strictly followed and anonymization was performed in accordance with Swiss State and Federal Law (The Swiss Federal Council, 2013; The Federal Assembly of the Swiss Confederation, 2014) as well as adhering to the guidelines approved by the UK Department of Health and the National Health Services (Information Standards Board for Health and Social Care, 2013). 


\section{Statistical analysis}

Data was analysed using SPSS (IBM SPSS version 20, Armonk, New York, USA). All variables were descriptively reviewed and continuous data were checked for normality using a Kolmogorov-Smirnov test. The participant's location (UK vs. Switzerland), age, gender or type of malocclusion were identified as potential influencing variables and associations with the confidence score were evaluated using Mann-Whitney U-tests for categorical data and Spearman's rank correlations for continuous data. In order to analyse the impact of the influencing variables on the reported motivating factors, Pearson's chi-squared tests were computed and, wherever significant, odds ratios (OR) included. P values less than 0.05 were considered statistically significant.

\section{Results}

In total, 204 questionnaires were distributed and the response was high (99.0\%), with only 2 questionnaires not returned. In 18 cases, the patients did not rate their confidence and in 5 cases demographic data was not collected. An overview of the percentage return and data collected is shown in Table 1.

Demographic data and details of malocclusions are given in Table 2 and Figures 1 and 2 , respectively. The age of the participants did not follow a normal distribution $(\mathrm{p}<0.001$ for both sites). The data for the different motivating factors and the confidence scores are shown in Table 3 and Figures 3 and 4. The reported confidence scores were left-skewed and did not follow a normal distribution ( $\mathrm{p}<0.001$ for both sites), therefore non-parametric analysis was undertaken.

In order to address the impact of the variables (i.e. location, gender, age and type of malocclusion) on the reported motivating factors, Pearson's chi-squared tests were performed and the results are presented in Table 4. It was apparent that location had some significant 
effects on what patients wanted to gain from orthognathic treatment. Patients in the UK centre were significantly more likely than their Swiss counterparts to state they would like improvements in dental aesthetics (OR: 6.1; 95\% CI: 3.1 to 12.1 ), facial aesthetics (OR: 2.4; 95\% CI: 1.3 to 4.6 ) and psycho-social health (OR: 4.1; 95\% CI: 1.9 to 8.5 ). The Swiss patients involved in this audit were significantly more likely to want to be free from pain (OR: 3.6; $95 \%$ CI: 1.3 to 9.9 ) and improve their breathing (OR: $6.0 ; 95 \%$ CI: 1.1 to 33.7 ) than their UK counterparts.

Gender only had an impact where facial aesthetics was concerned, with females being significantly more likely than males to want facial aesthetic changes in both the UK (OR: 2.3; 95\% CI: 1.1 to 4.6 ) and Swiss centres (OR: 4.6; 95\% CI: 1.4 to 14.7 ). The type of malocclusion had a limited impact. In the Swiss centre, patients who had an anterior open bite were significantly more likely to state that they would like to have improvements in dental aesthetics than patients without an anterior open bite (OR: $4.0 ; 95 \%$ CI: 1.0 to 15.0$)$. In the UK centre, Class II patients were significantly more likely to want resolution of pain than non-Class II patients (OR: 4.63; 95\% CI: 1.05 to 20.36), whereas Class III patients were significantly less likely to seek treatment for alleviation of pain than non-Class III patients (OR: $0.13 ; 95 \%$ CI: 0.03 to 0.69 ).

In order to assess whether the reported confidence scores were significantly influenced by location, gender, age and type of malocclusion, Mann-Whitney U-tests and Spearman's rank correlations were utilised where appropriate. These showed that the difference in confidence scores between the two sites was not statistically significant $(\mathrm{p}=0.186$, see Table 5), nor were the confidence scores affected by age or by type of malocclusion. In the Swiss centre, gender significantly affected the reported confidence score (Table 5), with females reporting a lower degree of confidence $(86.0 \% \pm 12.9 \%)$ compared with males $(92.8 \%$ $\pm 7.2 \%)$. This gender effect was not found in the UK cohort. 


\section{Discussion}

This audit explored motivating factors for orthognathic patients in two centres and also investigated how confident patients were that they would be satisfied with the outcome of their treatment. The sample size and the percentage completion of questionnaires were sufficient to allow conclusions to be drawn.

The different motivating factors were categorized from an open-ended question and the results concur with previous investigations which have identified functional and aesthetic factors to be the main reasons for patients undergoing orthognathic treatment (Olson and Laskin, 1980; Ostler and Kiyak, 1991; Cunningham et al., 1995; Finlay et al., 1995; Forssell et al., 1998; Nurminen et al., 1999; Stirling et al., 2007; Espeland et al., 2008; Oland et al., 2011; Yu et al., 2013). Moreover, the reported reasons for seeking treatment all appeared to be realistic and there were no obviously unrealistic wishes expressed in these cohorts of patients. Function, aesthetics and psycho-social aspects of life have been found to improve after treatment (Bertolini et al., 2000; Turker et al., 2008; Rustemeyer et al., 2010), and patients have also reported increased levels of self-confidence and social skills (Cunningham et al., 1995).

Previous investigations have tended to use closed questions when investigating motivating factors and expectations. This might be advantageous for categorizing data, but is fundamentally problematic, as it may "force" patients to select certain options and may not include all possible factors, resulting in under-recording. The use of an open-ended question allowed for a more unbiased approach and an in depth analysis of patients' wishes.

All patients reported a number of motivating factors and one may conclude that motivating factors for orthognathic treatment are diverse and patient specific. This highlights the need to elicit all motivating factors from individual patients in the pre-treatment phase, in 
order to determine if orthognathic treatment is in their best interests. Additionally, pain and breathing were reported as concerns, two factors which are often overlooked.

When analysing whether any of the demographic factors affected what patients hoped to gain from treatment it was apparent that age, gender and type of malocclusion did not appear to have a major influence on these factors. Conversely, location (UK vs. Switzerland) did impact on the responses given. Where significant differences were observed between the UK and Swiss centres, the odds ratios ranged between 2.4 (for facial aesthetics) and 6.1 (for dental aesthetics), demonstrating considerable clinical relevance. Two possible explanations for the variation in motivating factors between the two countries are that this may be a reflection of the socio-cultural differences between the populations and/or that the findings may be due to differences in information given to the patients by the clinical teams. Clinicians should therefore be prudent when considering the results of research into orthognathic patients' wishes when the research has been carried out in different clinics or countries.

One finding which was evident in both centres was that females were more likely to be motivated by improvements in facial aesthetics than males. This observation is in agreement with previous investigations with European patients (Athanasiou et al., 1989), but is in contrast with published data for an Asian population, where improvement in facial aesthetics was considered equally important for both genders (Yu et al., 2013).

In the past, some authors have argued that it is not essential for surgeons to recognize patients" "hidden" motives, since most patients seek orthognathic treatment for the same reasons (Olson and Laskin, 1980). Based on the results of the current study, it appears that reasons for seeking treatment are multifaceted, complex, include more than just function and aesthetics and may be subject to socio-cultural influences. Hence, the authors of this study see a thorough analysis of the patients' motives and expectations as an essential part of ensuring a successful outcome. The suggestion that clinicians should understand not only the disease, but 
also the patient (Ryan et al., 2012a), remains unchallenged and this investigation makes clear that understanding the patient includes the socio-cultural context as well as physical aspects. Clinicians must be cognizant that different geographical locations may be associated with different expectations and motivational factors and socio-cultural divergences may prompt variations in the above.

The second part of the study analysed the patients' confidence scores and the results demonstrated high levels of confidence in both centres, with no significant differences between the two centres. Although the Swiss females involved in the audit had lower levels of confidence in the outcome than males ( $86 \%$ vs. 92.8\%), location, age or type of malocclusion did not significantly influence the level of confidence. The results also support the general assumption that confidence in treatment outcome remains unaffected by the underlying malocclusion or age.

On an individual level, the ramifications of the confidence scores may be of clinical relevance. As outlined in the introduction, patients who anticipate problems appear to be more likely to exhibit dissatisfaction with treatment outcomes (Kiyak et al., 1988). In both countries, the confidence scores were skewed and the figures illustrate that there were only a small number of patients who lacked confidence in the outcomes. Thus, the confidence score introduced in this study could be a simple and clinically valuable tool to detect patients who may be at increased risk of post-treatment dissatisfaction.

Finally, the limitations of this audit must be addressed. The problems in interpreting international comparative research are well known (Øvretveit, 1998). Caution should also be exercised when assuming that location reflects socio-cultural differences, as the information given to the patients on the different clinics could potentially have influenced the responses also. Moreover, the sample size, although adequate for descriptive statistics, is small for inferences, and the confidence intervals are wide. Nevertheless, the significance levels 
achieved in the statistical testing and the odd ratios do show some statistical findings and it seems likely that these were true differences.

\section{Conclusions}

Based on this cross-national questionnaire given to pre-surgical orthognathic patients in two centres, the motivating factors appear to be affected more by location than by demographic factors (gender and age) or by the underlying malocclusion. The confidence scores for anticipated satisfaction with treatment outcome were equally high in both cohorts, and patients were generally confident that their motives for seeking orthognathic treatment would be adequately addressed.

\section{Acknowledgments}

This research did not receive any specific grant from funding agencies in the public, commercial, or not-for-profit sectors. 


\section{References}

Alanko OME, Svedström-Oristo A-L, Tuomisto MT: Patients' perceptions of orthognathic treatment, well-being, and psychological or psychiatric status: a systematic review. Acta Odontol Scand 68: 249-260, 2010

Athanasiou AE, Melsen B, Eriksen J: Concerns, motivation, and experience of orthognathic surgery patients: a retrospective study of 152 patients. Int J Adult Orthodon Orthognath Surg 4: 47-55, 1989

Bertolini F, Russo V, Sansebastiano G: Pre- and postsurgical psycho-emotional aspects of the orthognathic surgery patient. Int J Adult Orthodon Orthognath Surg 15: 16-23, 2000

Chew MT, Sandham A, Soh J, Wong HB: Outcome of Orthognathic Surgery in Chinese Patients. Angle Orthod 77: 845-850, 2007

Cunningham SJ, Hunt NP, Feinmann C: Psychological aspects of orthognathic surgery: a review of the literature. Int J Adult Orthodon Orthognath Surg 10: 159-172, 1995

Cunningham SJ, Johal A: Orthognathic correction of dento-facial discrepancies. Br Dent J 218: 167175,2015

Espeland L, Hogevold HE, Stenvik A: A 3-year patient-centred follow-up of 516 consecutively treated orthognathic surgery patients. Eur J Orthod 30: 24-30, 2008

Finlay PM, Atkinson JM, Moos KF: Orthognathic surgery: patient expectations; psychological profile and satisfaction with outcome. Br J Oral Maxillofac Surg 33: 9-14, 1995

Forssell H, Finne K, Forssell K, Panula K, Blinnikka LM: Expectations and perceptions regarding treatment: a prospective study of patients undergoing orthognathic surgery. Int J Adult Orthodon Orthognath Surg 13: 107-113, 1998

Information Standards Board for Health and Social Care: Anonymisation Standard for Publishing Health and Social Care Data Specification, ISB1523 Amd 20/2010. 2013

Kiyak HA, Vitaliano PP, Crinean J: Patients' expectations as predictors of orthognathic surgery outcomes. Health Psychol 7: 251-268, 1988

Nurminen L, Pietila T, Vinkka-Puhakka H: Motivation for and satisfaction with orthodontic-surgical treatment: a retrospective study of 28 patients. Eur J Orthod 21: 79-87, 1999

Oland J, Jensen J, Elklit A, Melsen B: Motives for surgical-orthodontic treatment and effect of treatment on psychosocial well-being and satisfaction: a prospective study of 118 patients. $\mathrm{J}$ Oral Maxillofac Surg 69: 104-113, 2011

Olson RE, Laskin DM: Expectations of patients from orthognathic surgery. J Oral Surg 38: 283-285, 1980

Ostler S, Kiyak HA: Treatment expectations versus outcomes among orthognathic surgery patients. Int J Adult Orthodon Orthognath Surg 6: 247-255, 1991

Øvretveit J: Comparative and cross-cultural health research: a practical guide. Radcliffe Medical Press, Abingdon, UK. 1998 
Rustemeyer J, Eke Z, Bremerich A: Perception of improvement after orthognathic surgery: the important variables affecting patient satisfaction. Oral Maxillofac Surg 14: 155-162, 2010

Ryan FS, Barnard M, Cunningham SJ: Impact of dentofacial deformity and motivation for treatment: a qualitative study. Am J Orthod Dentofacial Orthop 141: 734-742, 2012a

Ryan FS, Barnard M, Cunningham SJ: What Are Orthognathic Patients' Expectations of Treatment Outcome-A Qualitative Study. J Oral Maxillofac Surg 70: 2648-2655, 2012b

Stirling J, Latchford G, Morris DO, Kindelan J, Spencer RJ, Bekker HL: Elective orthognathic treatment decision making: a survey of patient reasons and experiences. J Orthod 34: 113-127, 2007

The Federal Assembly of the Swiss Confederation: Human Research Act (810.30), Art. 2 and Art 32. 2014

The Swiss Federal Council: Human Research Ordinance (810.301), Art. 25. 2013

Turker N, Varol A, Ogel K, Basa S: Perceptions of preoperative expectations and postoperative outcomes from orthognathic surgery: part I: Turkish female patients. Int J Oral Maxillofac Surg 37: 710-715, 2008

World Medical Association (WMA): Declaration of Helsinki - Ethical Principles for Medical Research Involving Human Subjects. 64th WMA General Assembly, Fortaleza, Brazil. 2013

Yu D, Wang F, Wang X, Fang B, Shen SG: Presurgical motivations, self-esteem, and oral health of orthognathic surgery patients. J Craniofac Surg 24: 743-747, 2013 


\section{Figure captions}

Figure 1: Age distribution of patient sample at the UK (left, in purple, $n=149)$ and Swiss centres (right, in green, $n=53$ )

Figure 2: Distribution of type of malocclusion for each centre (UK: left, in purple, $n=144$; and in Switzerland: right, in green, $n=53)$

Figure 3: Distribution of reported motivational factors, for each centre (UK: left, in purple, $n=149$; and in Switzerland: right, in green, $n=53)$.

Figure 4: Distribution of patient reported confidence (score 0-100\%), for each centre (UK: left, in purple, $n=131$; and in Switzerland: right, in green, $n=52$ ) 
Age distribution U.K.

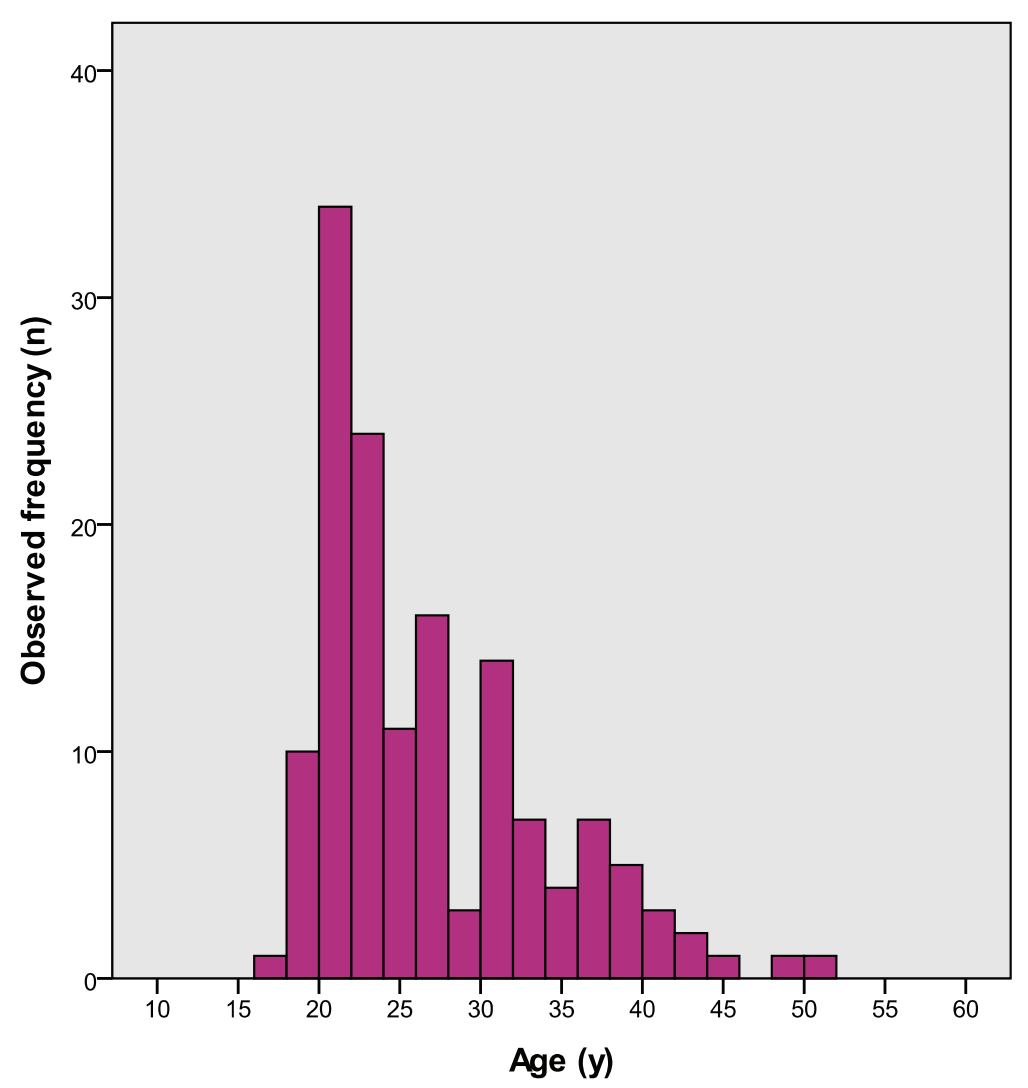

Age distribution Switzerland

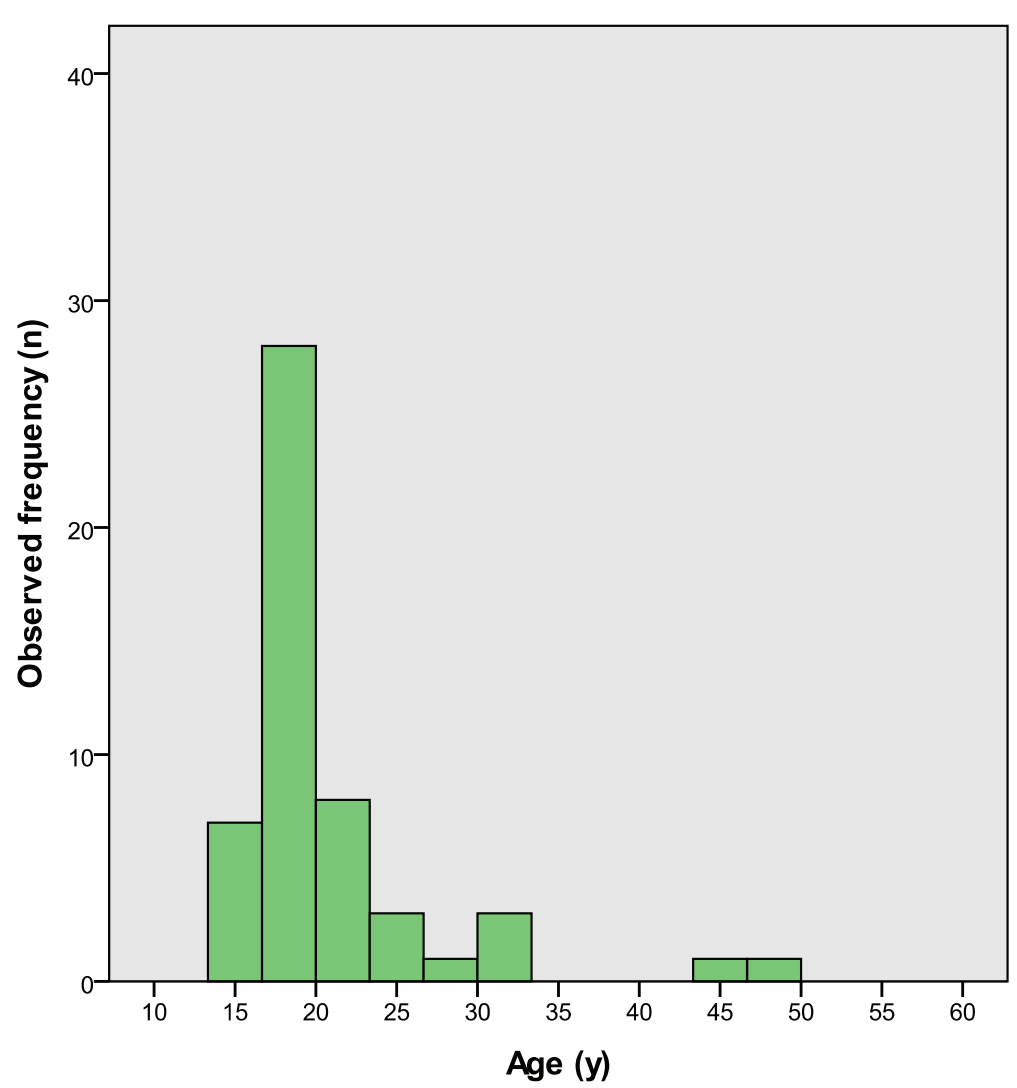


Type of malocclusion U.K.

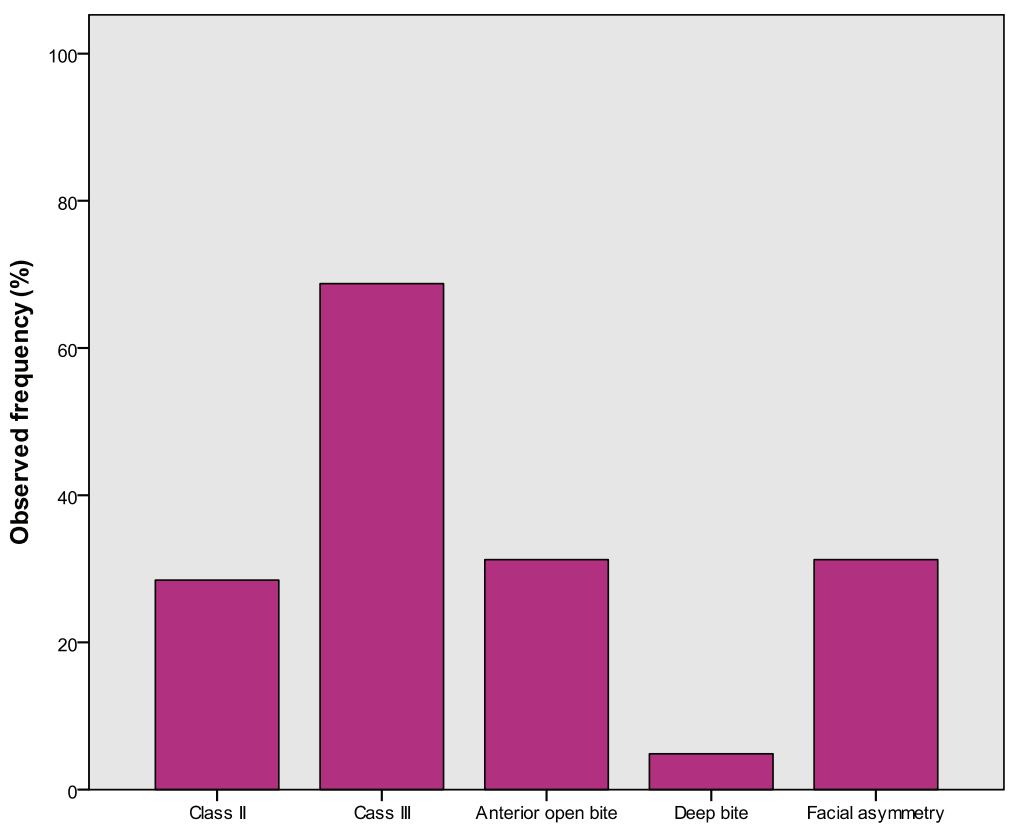

Type of malocclusion Switzerland

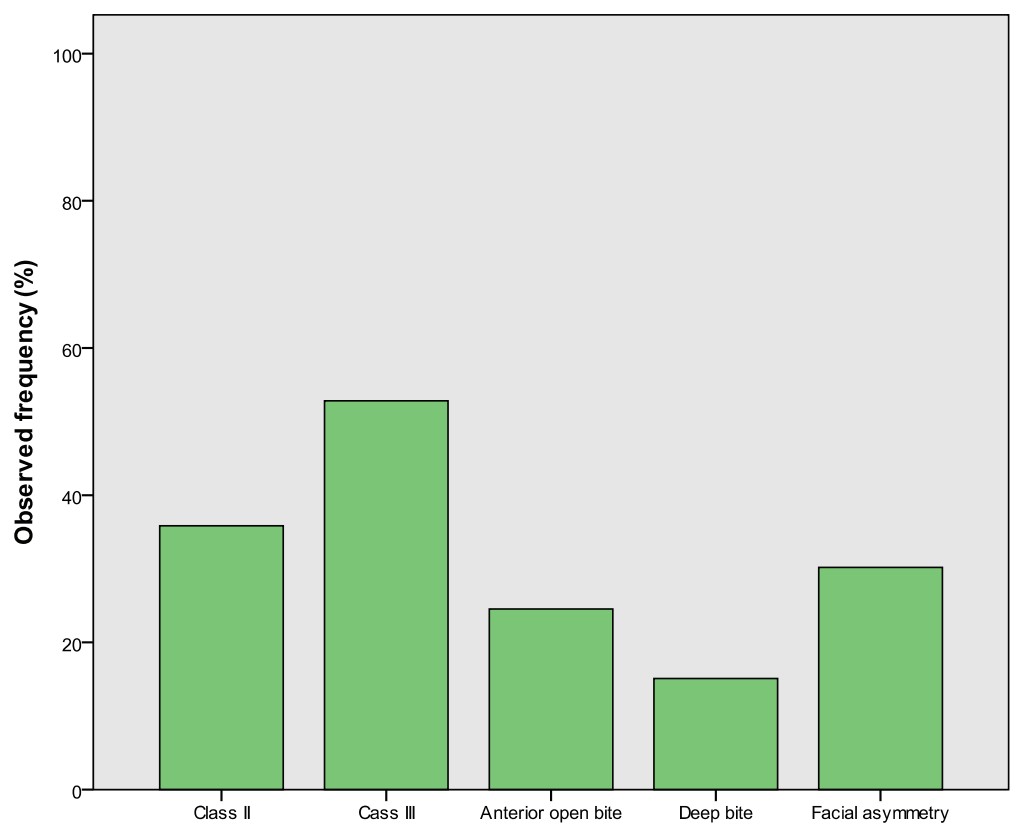


Figure 3

Expectations U.K.

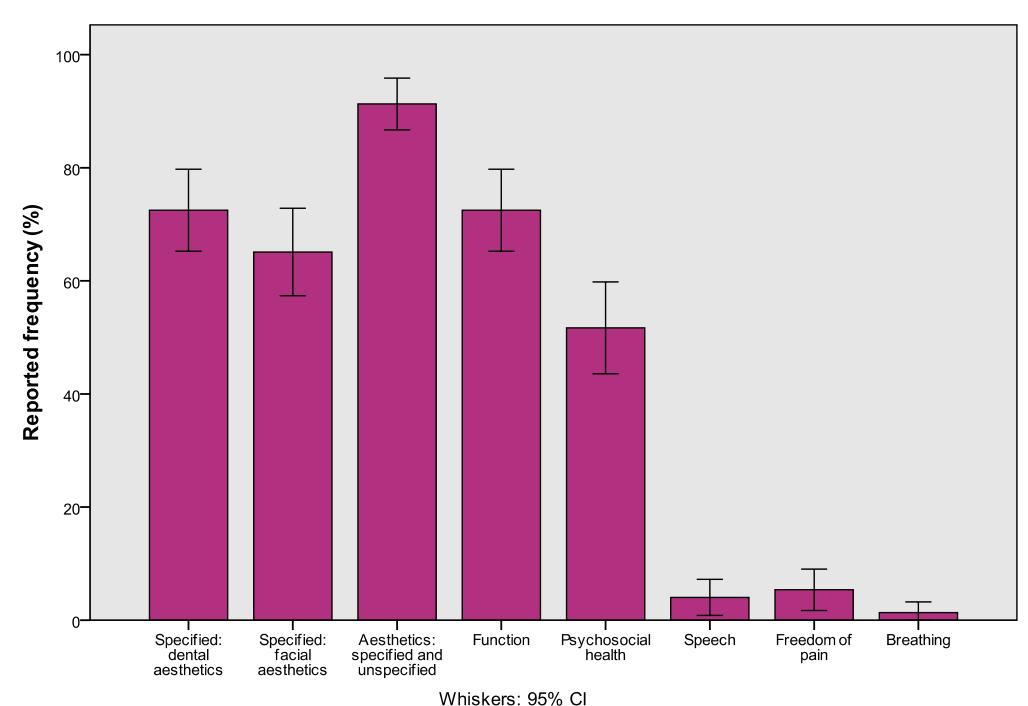

Expectations Switzerland

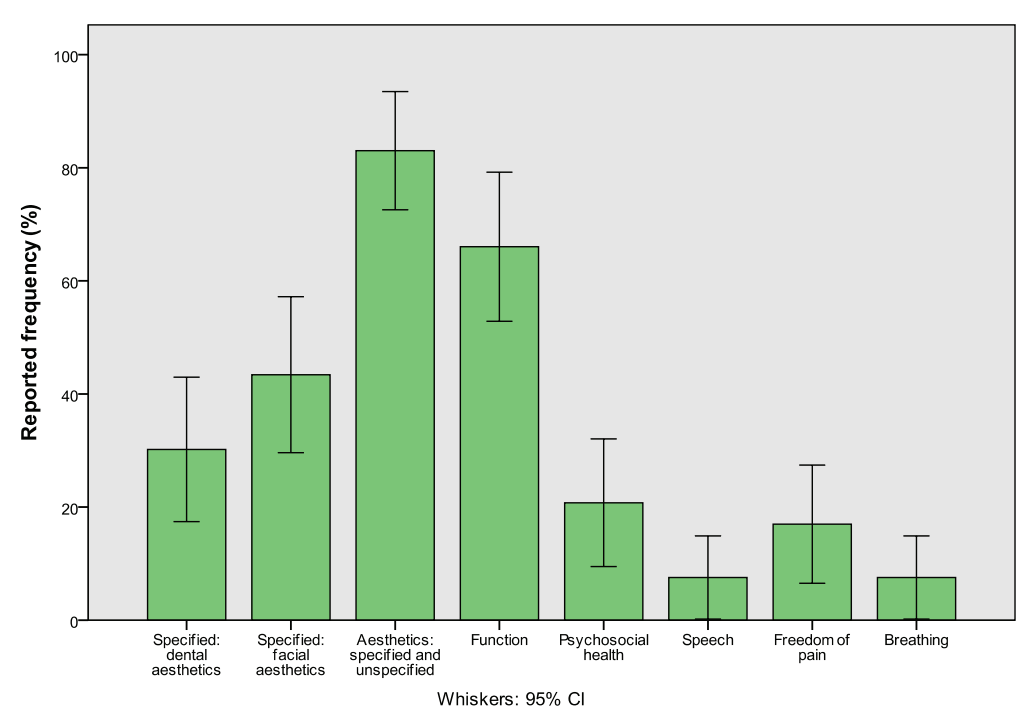


Confidence score U.K.

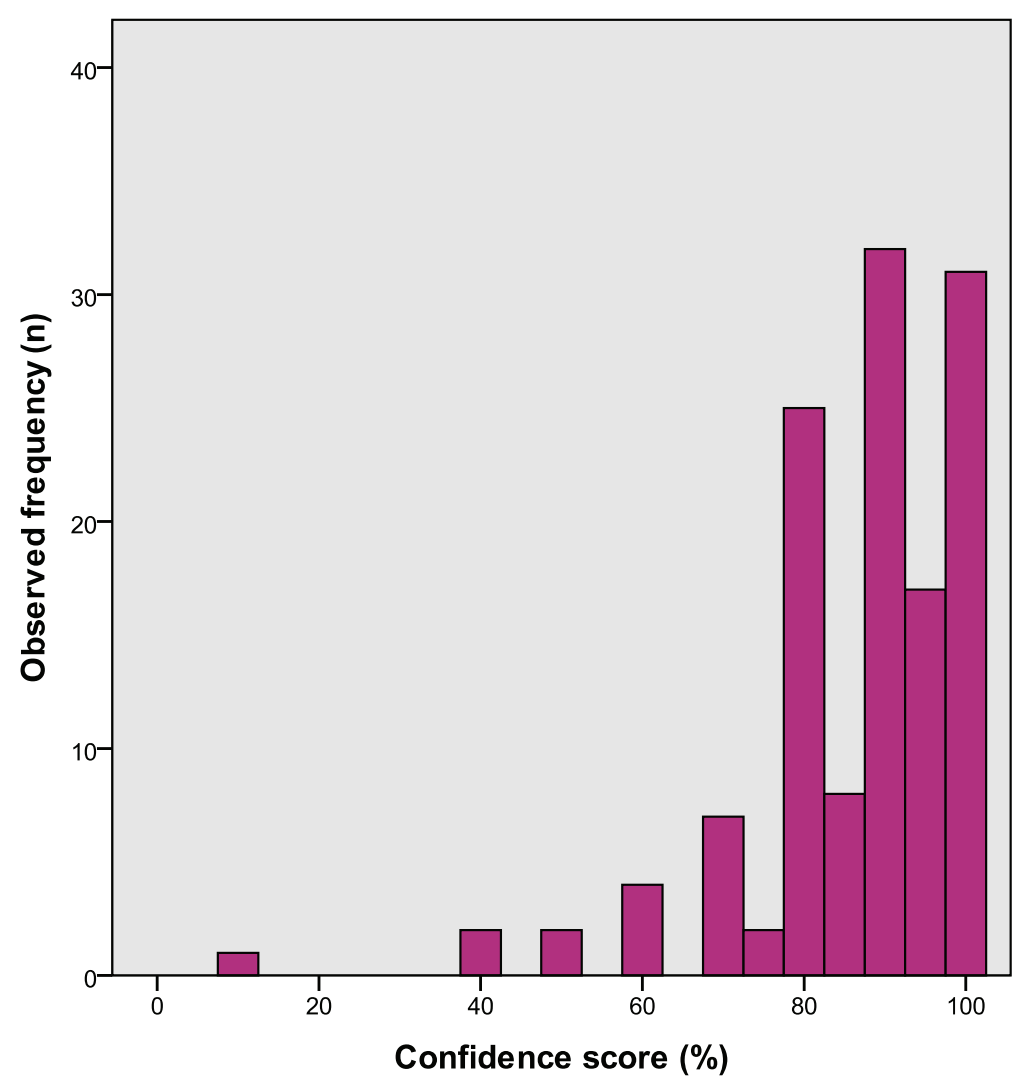

Confidence score Switzerland

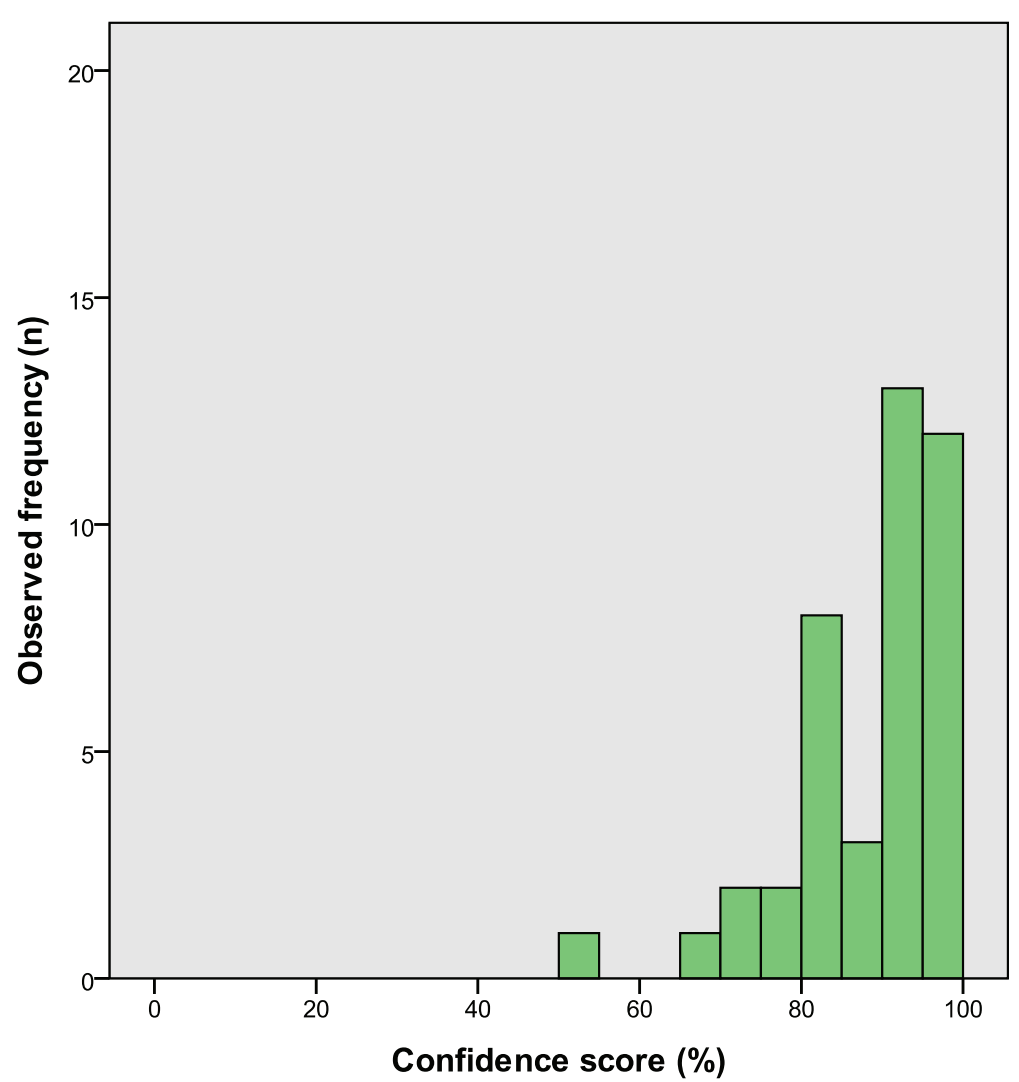




\section{Tables 1-5:}

Table 1: Data collection

\begin{tabular}{llr}
\hline Data & UK & Switzerland \\
\hline Distributed questionnaires (n) & 149 & 55 \\
Recollected questionnaires (n) & 149 & 53 \\
Questionnaires containing information on patient (n) «Influencing variables» & 144 & 53 \\
Questionnaires containing a confidence score (n) & 131 & 52 \\
Questionnaires containing information on motivations (n) & 149 & 53 \\
\hline
\end{tabular}

Table 2: Influencing variables (Age, gender, type of malocclusion) listed for each centre separately. SD: Standard deviation

\begin{tabular}{llcc}
\hline Variable & & UK $(\mathbf{n}=\mathbf{1 4 4})$ & Switzerland $(\mathbf{n}=\mathbf{5 3})$ \\
\hline Age $(\mathbf{y})$ & Mean (SD) & $26.43( \pm 7.1)$ & $20.94( \pm 6.75)$ \\
& Range & $17-51$ & $14-50$ \\
Gender & Females \% (n) & $52.1 \%(\mathrm{n}=75)$ & $49.1 \%(\mathrm{n}=26)$ \\
& Males \% (n) & $47.9 \%(\mathrm{n}=69)$ & $50.9 \%(\mathrm{n}=27)$ \\
Class II & $\%(\mathrm{n})$ & $28.5 \%(\mathrm{n}=41)$ & $35.8 \%(\mathrm{n}=19)$ \\
Class III & $\%(\mathrm{n})$ & $68.8 \%(\mathrm{n}=99)$ & $52.8 \%(\mathrm{n}=28)$ \\
Anterior open bite & $\%(\mathrm{n})$ & $31.3 \%(\mathrm{n}=45)$ & $24.5 \%(\mathrm{n}=13)$ \\
Deep bite & $\%(\mathrm{n})$ & $4.9 \%(\mathrm{n}=7)$ & $15.1 \%(\mathrm{n}=8)$ \\
Facial asymmetry & $\%(\mathrm{n})$ & $31.3 \%(\mathrm{n}=45)$ & $30.2 \%(\mathrm{n}=16)$ \\
\hline
\end{tabular}

Table 3: Outcome variables (confidence score and expected improvement. SD: Standard deviation

\begin{tabular}{|c|c|c|c|}
\hline Outcome variable & & UK & Switzerland \\
\hline \multirow[t]{2}{*}{ Confidence score (of obtaining a satisfactory result) } & Mean (SD) & $86.5( \pm 14.1)$ & $89.8( \pm 10.6)$ \\
\hline & Range & $10-100$ & $50-100$ \\
\hline \multicolumn{4}{|l|}{ Motivational factors reported: } \\
\hline . $\quad$ specified: dental aesthetics & $\%(n)$ & $72.5 \%(n=108)$ & $30.2 \%(n=16)$ \\
\hline - $\quad$ specified: facial aesthetics & $\%(n)$ & $65.1 \%(n=97)$ & $43.4 \%(n=23)$ \\
\hline - $\quad$ aesthetics: specified and unspecified & $\%(n)$ & $91.3 \%(n=136)$ & $83.0 \%(n=44)$ \\
\hline - function & $\%(n)$ & $72.5 \%(n=108)$ & $66.0 \%(n=35)$ \\
\hline - psychosocial health & $\%(n)$ & $51.7 \%(\mathrm{n}=77)$ & $20.8 \%(n=11)$ \\
\hline - speech & $\%(n)$ & $4.0 \%(n=6)$ & $7.5 \%(n=4)$ \\
\hline - freedom of pain & $\%(n)$ & $5.4 \%(n=8)$ & $17 \%(n=9)$ \\
\hline · $\quad$ breathing & $\%(n)$ & $1.3 \%(n=2)$ & $7.5 \%(n=4)$ \\
\hline
\end{tabular}


Table 4: Impact of independent variables (location, gender and type of malocclusion) on reported motivational factors.

\begin{tabular}{|c|c|c|c|c|c|c|c|c|}
\hline & $\begin{array}{c}\text { Specified: } \\
\text { dental } \\
\text { aesthetics }\end{array}$ & $\begin{array}{c}\text { Specified: } \\
\text { facial } \\
\text { aesthetics }\end{array}$ & $\begin{array}{l}\text { Aesthetics: } \\
\text { specified \& } \\
\text { unspecified }\end{array}$ & Function & $\begin{array}{c}\text { Psycho- } \\
\text { social } \\
\text { health }\end{array}$ & Speech & $\begin{array}{c}\text { Freedom } \\
\text { of pain }\end{array}$ & Breathing \\
\hline Location & $<0.001$ & 0.006 & n.s. & n.s. & $<0.001$ & n.s. & 0.009 & 0.022 \\
\hline Gender & n.s. & $\begin{array}{l}\text { UK: } 0.022 \\
\text { CH: } 0.009\end{array}$ & n.s. & n.s. & n.s. & n.s. & n.s. & n.s. \\
\hline Class II & n.s. & n.s. & n.s. & n.s. & n.s. & n.s. & $\begin{array}{c}\text { UK: } 0.028 \\
\text { CH: n.s. }\end{array}$ & n.s. \\
\hline Class III & n.s. & n.s. & n.s. & n.s. & n.s. & n.s. & $\begin{array}{c}\text { UK: } 0.006 \\
\text { CH: n.s. }\end{array}$ & n.s. \\
\hline $\begin{array}{l}\text { Anterior } \\
\text { open Bite }\end{array}$ & $\begin{array}{c}\text { UK: n.s. } \\
\text { CH: } 0.032\end{array}$ & n.s. & n.s. & n.s. & n.s. & n.s. & n.s. & n.s. \\
\hline Deep Bite & n.s. & n.s. & n.s. & n.s. & n.s. & n.s. & n.s. & n.s. \\
\hline $\begin{array}{l}\text { Facial } \\
\text { Asymmetry }\end{array}$ & n.s. & n.s. & n.s. & n.s. & n.s. & n.s. & n.s. & n.s. \\
\hline
\end{tabular}

Analysed with a Pearson's chi-squared test. Since location had a great influence on motivational factors, all other independent variables were checked for both locations independently. If no significance (n.s.) is reported, it applies to both locations.

* Only p-values with statistical significance are reported

Table 5: Statistical testing of those variables which may potentially affect confidence scores. Non-parametric tests evaluating the association between confidence score (dependent variable) and location, gender, age and type of malocclusion (independent variable).

\begin{tabular}{llcc}
\hline Influencing variable & Statistical test & UK & Switzerland \\
\hline & Confidence score: mean $(S D)$ & $86.5( \pm 14.1)$ & $89.9( \pm 10.6)$ \\
Location & Mann-Whitney U-test & & 0.186 \\
Gender & Mann-Whitney U-test & 0.675 & $\mathbf{0 . 0 3 8}$ \\
Age & Spearman's Rho & 0.771 & 0.155 \\
Class II & Mann-Whitney U-test & 0.461 & 0.289 \\
Class III & Mann-Whitney U-test & 0.634 & 0.344 \\
Anterior open bite & Mann-Whitney U-test & 0.190 & 0.050 \\
Deep bite & Mann-Whitney U-test & 0.095 & 0.502 \\
Facial asymmetry & Mann-Whitney U-test & 0.385 & 0.731 \\
\hline
\end{tabular}

* Statistical significance 